\title{
Use of negative pressure wound therapy in pediatric oncology patients: a single- center review of 66 patients
}

\author{
Stacy Wong ${ }^{1}$, Anas Eid ${ }^{2}$, Warren Southerland ${ }^{3}$, Jon P. Ver Halen ${ }^{1}$ \\ ${ }^{1}$ Department of Surgery, Division of Plastic Surgery, Baylor Scott and White Healthcare, Texas AEM School of Medicine, Temple, \\ TX 76513, USA. \\ ${ }^{2}$ Division of Plastic, Reconstructive and Hand Surgery, Baptist Cancer Center, Memphis, TN 38120, USA. \\ ${ }^{3}$ University of Tennessee Health Science Center, School of Medicine, Memphis, TN 38163, USA. \\ Correspondence Author: Dr. Jon P. Ver Halen, Department of Surgery, Division of Plastic Surgery, Baylor Scott and White Healthcare, \\ Texas A\&M School of Medicine, 1016 Crescent Drive Belton, Temple, TX 76513, USA. E-mail: jpverhalen@gmail.com
}

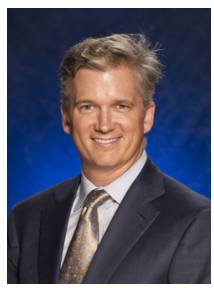

Dr. Jon P. Ver Halen is currently an Associate Professor with the Texas A\&M School of Medicine, Department of Surgery. He is also Associate Program Director of the Plastic Surgery Residency, and Program Director of the Microvascular Surgery Fellowship.

\section{ABSTRACT}

Aim: Negative pressure wound therapy (NPWT) has been studied extensively in adult patients, but less is known about pediatric patients. This study assesses the efficacy and safety of vacuumassisted closure ${ }^{\circledast}$ usage in pediatric oncology patients. Methods: Retrospective data on all patients treated with NPWT at a single pediatric oncology hospital were collected between April 2005 and September 2013. Details on pre-treatment factors, treatment course, and post-treatment events were collected. No control group was available for comparison. Results: Sixty-six patients were identified, with a total of 74 wounds. Median age at the time of NPWT application was 13 years (range, 10 months-23 years). Median duration of treatment was 21 days (range, 3-236 days). NPWT therapy was started with continuous high negative pressures $(125 \mathrm{mmHg})$ in most patients. Sixty-nine percent of patients had their wounds healed without intervention, and $20 \%$ of patients required surgical closure. NPWT was discontinued temporarily secondary to skin maceration or cellulitis in $12 \%$ of patients. NPWT was used in a number of non-standard clinical situations, including primarily-closed incisional wound NPWT and bridging NPWT through adjuvant chemotherapy. Conclusion: In pediatric oncology patients, NPWT is safe, effective, and well-tolerated. Although this study is retrospective in nature, and there was no control group for comparison, these data are important for clinicians to guide therapy as device monitoring agencies and payors increasingly require outcomes data for the approval of therapeutic decisions.

\section{Key words:}

Pediatric; oncology; negative pressure wound therapy

\begin{tabular}{|l|l|}
\hline \multicolumn{2}{|c|}{ Access this article online } \\
\hline Quick Response Code: & Website: \\
\hline $\mathbf{y}$ & http://www.parjournal.net \\
\cline { 2 - 3 } & \\
\hline $\mathbf{D}$ & DOI: \\
\hline
\end{tabular}

This is an open access article distributed under the terms of the Creative Commons Attribution-NonCommercial-ShareAlike 3.0 License, which allows others to remix, tweak and build upon the work non-commercially, as long as the author is credited and the new creations are licensed under the identical terms.

For reprints contact: service@oaepublish.com

How to cite this article: Wong S, Eid A, Southerland W, Ver Halen JP. Use of negative pressure wound therapy in pediatric oncology patients: a single-center review of 66 patients. Plast Aesthet Res 2016;3:248-53.

Received: 08-09-2015; Accepted: 06-06-2016 


\section{INTRODUCTION}

Negative pressure wound therapy (NPWT) has fundamentally changed complex wound management, such that it is now considered an independent rung on the "reconstructive ladder." ${ }^{[1-4]}$ NPWT therapy has been studied extensively in adults, where it has found applications in chronic wounds, open abdominal wounds, and open fractures, amongst others. ${ }^{|5-8|}$ Recent studies have showed that outcomes in the pediatric population are often equivalent to those reported in adults. ${ }^{[9-12]}$ However, no large studies have examined the use of NPWT in the pediatric oncology population, a group which is unique given the frequent utilization of extensive surgery, systemic chemotherapy, radiotherapy, and (in some cases) stem cell transplantation. ${ }^{[13 \mid}$ In this study, we reviewed our single-center experience with NPWT in pediatric oncology patients and reported our outcomes with respect to efficacy, safety, and technical innovation in wound treatment.

\section{METHODS}

Records of patients treated with NPWT at a single center between April 2005 and September 2013 were reviewed. Approval for the study was obtained from the institutional review board of the respective institution. Patient data included demographics, diagnosis, and duration of NPWT, adjunctive treatment, wound size, definitive wound closure technique, complications, chemotherapy, radiation, recurrent disease, and general outcomes.

All NPWT systems used in this study were designed and manufactured by Kinetic Concepts, Incorporated (KCI Inc, San Antonio, TX, USA). The device includes a vacuum-assisted cosure ${ }^{\circledR}$ (VAC) dressing (wound VAC ${ }^{\circledR}$ dressing), consisting of a polyurethane or polyvinyl sponge placed directly over a wound site. The sponge is then sealed with plastic tape and connected to a negative pressure device with a tube. The vacuum pump in the device creates a sub-atmospheric negative pressure in the wound bed, and it is reported to reduce edema, increase local blood supply, increase the formation of granulation tissue, reduce bacterial colonization, improve patient tolerance, and accelerate wound healing overall. ${ }^{[14,15]}$

\section{RESULTS}

Between April 2005 and September 2013, a total of 66 patients were identified for study inclusion. Seven patients required multiple wound VAC, or a wound VAC at multiple times, for a total number of 74 wounds treated with NPWT. Patient and wound characteristics at baseline are reported in Table 1 . The median patient age was 13 years, with a range of 10 months to 18 years.
Table 1: Patient and wound characteristics at baseline $(n=66)$

\begin{tabular}{|c|c|}
\hline \multicolumn{2}{|l|}{ Patient characteristics } \\
\hline Age at NPWT application, median (range) & $\begin{array}{c}3 \text { years (10 months-18 } \\
\text { years) }\end{array}$ \\
\hline Gender & 31 females; 35 males \\
\hline Body mass index $\left(\mathrm{kg} / \mathrm{m}^{2}\right)$, median (range) & $21.5(14.1-45.9)$ \\
\hline Serum albumin (g/dL), median (range) & $4.2(2.5-4.8)$ \\
\hline Patients using NPWT during chemotherapy & 22 \\
\hline Patients receiving chemotherapy & 56 \\
\hline Patients receiving radiation & 24 \\
\hline Wound size $\left(\mathrm{cm}^{2}\right)$, median (range) & $27(4-250)$ \\
\hline $\begin{array}{l}\text { Time until wound closure (days), } \\
\text { median (range) }\end{array}$ & $21(3-236)$ \\
\hline $\begin{array}{l}\text { Duration of wound NPWT (days), } \\
\text { median (range) }\end{array}$ & $21(3-236)$ \\
\hline
\end{tabular}

NPWT: negative pressure wound therapy

Table 2: Pathologic diagnosis of primary tumors

\begin{tabular}{lc}
\hline Primary disease & Number of patients \\
\hline Osteosarcoma & 30 \\
Ewing sarcoma & 6 \\
Retinoblastoma & 2 \\
Acute lymphoblastic leukemia & 6 \\
Acute myeloid leukemia & 2 \\
Adrenocortical carcinoma & 1 \\
Dermatofibrosarcoma protuberans & 1 \\
Epitheloid sarcoma & 1 \\
Glioma & 1 \\
Hodgkins lymphoma & 1 \\
Melanoma & 2 \\
Malignant fibrous histiocytoma & 1 \\
Malignant peripeheral nerve sheath tumor & 2 \\
Soft tissue high grade polyphenotypic sarcoma & 1 \\
Rabdomyosarcoma & 1 \\
Sickle cell anemia & 1 \\
Synovial sarcoma & 5 \\
Malignant teratoma of the sacral bone & 1 \\
Thalamic glioblastoma & 1 \\
\hline
\end{tabular}

Our sample had 35 males to 31 females. The median body mass index (BMI) was $21.5 \mathrm{~kg} / \mathrm{m}^{2}$ (range, 14.1-45.9 kg/m²). Only 5 patients had serum albumin less than $3.4 \mathrm{mg} / \mathrm{L}$, and only 1 patient had serum albumin less than $3.1 \mathrm{mg} / \mathrm{L}$. There was no association between serum albumin level and adverse events $(P>0.05)$. Wounds were primary wounds in 62 patients, and recurrent in 4 patients.

Patient primary diagnoses are reported in Table 2. Fifty-six patients received chemotherapy at some point during their cancer therapy, and 22 of these patients had wounds requiring NPWT during chemotherapy. In these latter patients, NPWT was used for a range of 21-206 days. Twenty-four patients received radiation therapy at some point during their cancer treatment. Of these patients, the radiation dose was administered to the site of the wound in all but nine cases.

NPWT was used in total of 66 patients. Three patients 
Table 3: Wound etiology in patients $(n=66)$

\begin{tabular}{lc}
\hline Wound etiology & Number of patients \\
\hline Trauma & 2 \\
Wound dehiscence & 2 \\
Post-surgical & 56 \\
Skin infection & 1 \\
Pressure sore & 1 \\
Sickle-cell/vascular disease & 1 \\
Cutaneous acute lymphoblastic leukemia & 1 \\
Purpura fulminans & 1 \\
Extravasation injury & 1 \\
\hline
\end{tabular}

Table 4: Indication for negative pressure wound therapy $(n=66)$

\begin{tabular}{lc}
\hline Indication & Number of patients \\
\hline Local wound care & 44 \\
Skin graft/Integra fixation & 11 \\
Brachytherapy & 1 \\
Support of primarily-closed incision & 10 \\
\hline
\end{tabular}

Table 5: Anatomic location of wounds, and exposed structures at wound base (wounds $=74$ )

\begin{tabular}{lc}
\hline & Number of wounds \\
\hline Wound location & 4 \\
Head and neck & 13 \\
Trunk & 10 \\
Upper extremity & 47 \\
Lower extremity & \\
Exposed structures & 11 \\
Bone & 4 \\
Fascia & 7 \\
Tendon & 3 \\
Nerve & 2 \\
Endoprosthesis & 11 \\
Skin (incisional wound VAC) & 36 \\
Muscle or fat & \\
\hline
\end{tabular}

VAC: vacuum-assisted closure

Table 6: Outcomes of negative pressure wound therapy utilization $(n=66)$

\begin{tabular}{lc}
\hline & Number of patients \\
\hline $\begin{array}{l}\text { Mechanism of closure in healed } \\
\text { wounds }\end{array}$ & $(\boldsymbol{n}=\mathbf{6 0 )}$ \\
Secondary intention & 47 \\
Skin graft/Integra & 6 \\
Local flap/tissue closure & 4 \\
$\quad$ Delayed primary closure & 3 \\
Characteristics of non-healing & $(\boldsymbol{n}=\mathbf{6 )}$ \\
wounds & 2 \\
Wound recurrence & 1 \\
Died of primary disease before & \\
wound closure & 1 \\
Died of necrotizing fasciitis & 2 \\
Amputation & \\
\hline
\end{tabular}

had NPWT therapy twice: once before reconstruction and again for skin graft fixation. One patient had NPWT applied three times: first, for local wound care; second, for fixation of integra dermal regeneration template (Integra Life Sciences, Plainsborough, New Jersey, USA); and third, for skin graft fixation. Three patients had two separate wounds, requiring two separate wound VACs. In total, NPWT was used 74 times in 66 patients.

Wound etiology is presented in Table 3. Fifty-six patients had surgically-created wounds. Two patients had traumatic wounds. Two patients had wound dehiscence requiring NPWT. One patient had pressure ulcer. There was one case of sickle-cell induced avascular skin necrosis. One case of cutaneous acute lymphoblastic leukemia resulted in full thickness skin loss. One patient with osteosarcoma who was treated with methotrexate developed a case of purpura fulminans that required debridement and NPWT. One wound resulted after debridement of a cutaneous infection. There was one wound that resulted after an extravasation injury. Three patients had amputations that required NPWT; 2 of them for open wounds and 1 for an incisional wound. NPWT was applied immediately in the event of surgicallycreated wounds, and it was delayed for a range of 1 to 21 days in the remaining patients.

NPWT indication is shown on Table 4. NPWT was used for local wound care in 44 patients, skin graft and/or integra fixation in 10 patients, local wound care in the setting of brachytherapy in one patient, and incisional support in 11 patients. With respect to incisional NPWT, 4 patients had previous external beam radiation therapy, and 2 patients had previous brachytherapy. There were 10 extremity wounds and 1 scalp wound that utilized incisional NPWT. All wounds were healed without complications at the time incisional NPWT was discontinued (5-7 days postoperatively).

Table 5 shows the anatomic distribution of wound NPWT usage. NPWT was used in the head and head/neck in three patients, trunk in 13 patients, upper extremity in 10 patients, and lower extremity in 40 patients. Eleven wounds had bone exposure in the wound bed; four had exposure of fascia; seven had tendon exposure; three had nerve exposure; and two patients had exposure of their endoprostheses. The remaining had either skin, fat, or muscle exposed.

The respective wounds ultimately healed in 60 patients [Table 6]. Wounds healed by secondary intention in 47 patients, skin grafting in four patients, adjacent tissue transfer in three patients, split-thickness skin graft (STSG) and Integra in two patients, local flap in one patient, and delayed primary closure in three patients. Wounds failed to heal in 2 patients who had recurrence of their wound at last follow up, in 1 patient who died of necrotizing fasciitis, in 1 patient who died of primary disease, and in 2 of the 3 patients who required amputation. No patients required free flap to reconstruct their wound.

At the time of their last follow-ups, 2 patients had died of their primary disease. One patient died secondary to necrotizing fasciitis. One patient had a below-knee 


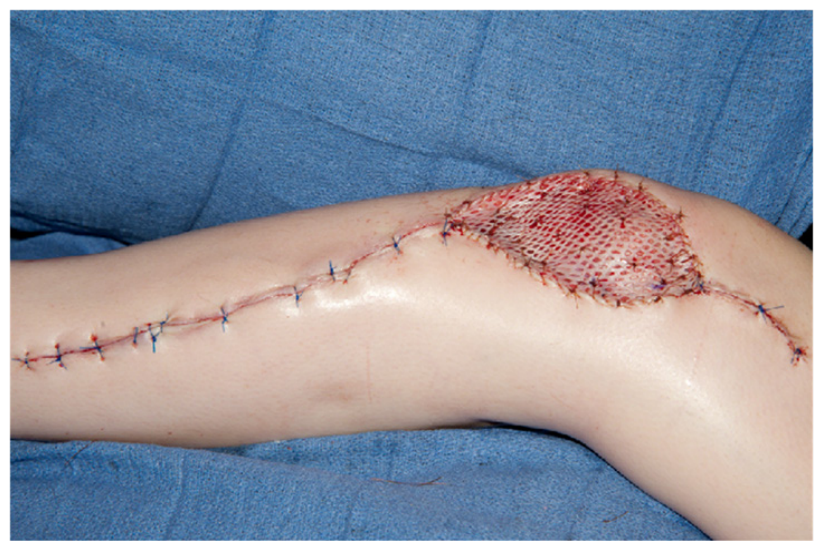

Figure 1: Right leg after limb-salvage procedure, with gastrocnemius muscle flap and skin graft coverage of central wound

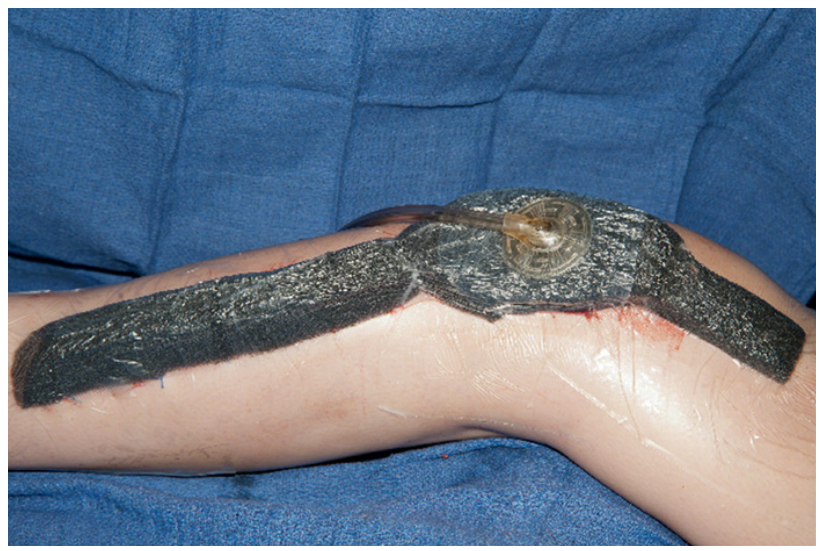

Figure 2: Surgical site with wound vacuum-assisted closure in place

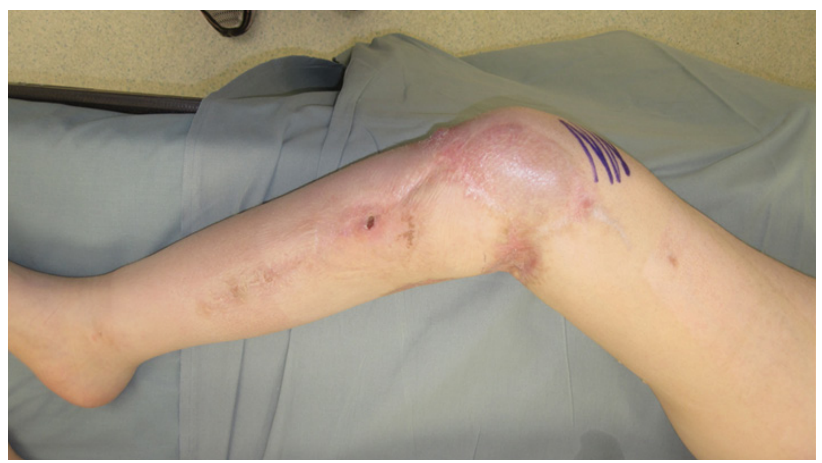

Figure 3: Surgical site after wound has healed

amputation secondary to intractable pain, unrelated to his wound. Three patients had above-knee amputations: 1 secondary to local tumor recurrence; 1 due to a failed free flap reconstruction; and 1 from implant failure.

NPWT was applied with a negative pressure of $125 \mathrm{mmHg}$, except in 1 scalp case in which the negative pressure was set to $75 \mathrm{mmHg}$. NPWT was used under continuous pressure except in 1 patient where intermittent pressure was used for a cheek wound. The regular black Granufoam sponge was used in all but 11 cases. Silverimpregnated Granu-foam sponges were used in 7 cases, and 1 case used the White-foam sponge for an open abdominal wound. The average wound size was $36 \mathrm{~cm}^{2}$ (median, $27 \mathrm{~cm}^{2}$; range, $4-250 \mathrm{~cm}^{2}$ ). The average number of days to achieve wound closure was 39 days, with a median of 21 days and a range of 3 to 236 days.

In general, patients tolerated NPWT with minimal morbidity. One patient who had NPWT for fixation of STSG developed cellulitis under the sponge secondary to methicillin-resistant Staphylococcus aureus. The cellulitis resolved after the discontinuation of the NPWT and healed completely with no further interventions. Seven patients developed maceration of the skin under the wound VAC dressing, requiring temporary discontinuation of NPWT.

\section{DISCUSSION}

Wound issues are not uncommon in the oncology population due to various factors including radiation, chemotherapy, and decreased immunity. ${ }^{[16-19]}$ NPWT has showed some promising results in the pediatric population. ${ }^{[12-15]}$ Our study assesses the safety and efficacy of NPWT therapy in the pediatric oncology population.

NPWT therapy offers several advantages over traditional wound care. Because dressing changes are only done every two to three days, the often painful dressing change experience is less traumatic, simplifying wound care for both the patient and the provider. Drainage of the wound is contained in a transparent container, and wound leakage is far less likely compared to traditional wound care. These factors help improve compliance and reduce patient anxiety regarding wound care.

In this study, most wounds were managed successfully with NPWT. The wound VAC was applied in all our patients without any problems regardless of the patient's age or the location or size of the wound.

Of the total 66 patients treated with NPWT, 69\% of the wounds healed completely with no intervention, and $20 \%$ required delayed surgical closure. NPWT was discontinued temporarily secondary to skin maceration or cellulitis in $12 \%$ of patients. Wound care was converted to traditional saline wetted gauze in those cases, and all wounds subsequently healed completely without surgical intervention. No problems of retained sponge material, device malfunction, or inability to apply the wound NPWT were reported in our study. Complications were seen in $12 \%$ of the patient population.

The indications for NPWT have expanded since its first introduction. We started using NPWT directly on primarily-closed incisions in the setting of previous radiation therapy, reoperation, and chronic steroid use in 2009. Initially described in patients with multiple comorbidities, this technique was met with moderate success and has resulted in the introduction of NPWT 
systems specifically tailored for this use [Figures 1-3]. ${ }^{[20-22]}$ In our study, no complications were reported with incisional wound NPWT. All wounds using the incisional NPWT system healed without issue, although use of the incisional NPWT was not randomized to establish a control group for comparison. However, from historical controls of similar patients, we would have expected a complication rate of $6-22 \%$. In addition to wound care, our study shared the same favorable outcomes of previous studies in using vacuum assisted fixation of STSG and Integra with acceptable complication rates. ${ }^{[23]}$

Another novel use of NPWT in our system involved using the VAC in patients with wound healing issues while undergoing concurrent chemotherapy. Specifically with regard to limb salvage patients, one of our protocols involved the use of bevacizumab (an angiogenesis inhibitor) and concurrent high-dose methotrexate. Postsurgical wound dehiscence or delayed wound healing in this population was not uncommon. Given the attendant myelosuppression in these patients, surgical wound closure frequently needed to be delayed. In such patients, wound care was often performed using NPWT for a prolonged period of time, with excellent results.

NPWT offers a safe and reliable alternative to traditional wound care. Our findings are equivalent to similar reports in other pediatric populations. ${ }^{[6,10]}$ Two cases did have severe complications in our series. In the first case the patient ultimately required a hemipelvectomy for definitive oncologic treatment; however, this complication was related to the nature of the wound rather than use of NPWT. The only wound-related mortality in our cohort was secondary to a case of Streptococcus pyogenes necrotizing fascitiis. The patient was a 9-year-old girl with acute lymphoblastic leukemia, status post allogeneic bone marrow transplant, and she was being treated with methotrexate and prednisone. She developed necrotizing fasciitis and underwent two rounds of surgical debridement of an abdominal wound before NPWT. She expired 3 days later. There was no evidence that the infection was due to the use of NPWT in this case. There was a reported case ${ }^{[24]}$ of necrotizing fasciitis in an adult paraplegic patient which occurred after NPWT for treatment of a debrided grade IV ischial pressure ulcer. The authors believed that the patient's underlying osteomyelitis and his prolonged wound VAC dressing change regimen (the dressing sponge was only changed every 5 days rather than the recommended 2 to 3 days regimen) may have contributed to the development of necrotizing fasciitis. There is no evidence in the literature that supports a correlation between the use of NPWT and an increased risk for the development of necrotizing fascitiis.

One of the limitations of our study is its retrospective nature. Because this study was observational, we lacked a control group to compare NPWT to traditional wound management in pediatric oncology patients. Another weakness is the lack of patients below six months of age; this patient population may require different approaches and different settings for NPWT. ${ }^{[25]}$ Another issue which was not addressed in our study is the use of continuous versus intermittent negative pressure. ${ }^{[26]}$ All our patients except one had continuous NPWT. There is experimental evidence that intermittent vacuum therapy promotes more granulation tissue formation than continuous therapy. ${ }^{[27]}$ Regardless of these limitations, our study suggests that the use of NPWT is a viable and safe tool in this pediatric oncology population.

In conclusion, we have found NPWT to be a valuable tool for the management of open wounds, fixation of skin grafts, and as a dressing for incision sites in children who are undergoing chemotherapy or radiation therapy. NPWT complications in this patient population are acceptable and easily manageable.

\section{Financial support and sponsorship}

Nil.

\section{Conflicts of interest}

There are no conflicts of interest.

\section{REFERENCES}

I. Dedmond BT, Kortesis B, Punger K, Simpson J, Argenta J, Kulp B Morykwas M, Webb LX. Subatmospheric pressure dressings in the temporary treatment of soft tissue injuries associated with type II open tibial shaft fractures in children.J Pediatr Orthop 2006;26:728-32.

2. Canavese F, Gupta S, Krajbich JI, Emara KM. Vacuum-assisted closure for deep infection after spinal instrumentation for scoliosis. J Bone Joint Surg $\mathrm{Br}$ 2008;90:377-8I.

3. Stannard JP, Volgas DA, Stewart R, McGwin G Jr, Alonso JE. Negative pressure wound therapy after severe open fractures: a prospective randomized study. J Orthop Trauma 2009;23:552-7.

4. McCord SS, Naik-Mathuria BJ, Murphy KM, McLane KM, Gay AN, Bob Basu C, Downey CR, Hollier LH, Olutoye OO. Negative pressure therapy is effective to manage a variety of wounds in infants and children. Wound Repair Regen 2007;15:296-30I.

5. Bütter A, Emran M, Al-jazaeri A, Ouimet A. Vacuum-assisted closure for wound management in the pediatric population. J Pediatr Surg 2006;41:940-2.

6. Caniano DA, Ruth B, Teich S. Wound management with vacuumassisted closure: experience in 51 pediatric patients. J Pediatr Surg 2005;40:128-32.

7. Contractor D, Amling J, Brandoli C, Tosi LL. Negative pressure wound therapy with reticulated open cell foam in children: an overview. J Orthop Trauma 2008;22:SI67-76.

8. Horn PL, Ruth B, Kean JR. Use of wound V.A.C. therapy in pediatric patients with infected spinal wounds: a retrospective review. Orthop Nurs 2007;26:317-22.

9. Baharestani MM. Use of negative pressure wound therapy in the treatment of neonatal and pediatric wounds: a retrospective examination of clinical outcomes. Ostomy Wound Manage 2007;53:75 85.

I0. Mooney JF 3rd, Argenta LC, Marks MW, Morykwas MJ, DeFranzo AJ. Treatment of soft tissue defects in pediatric patients using the V.A.C. system. Clin Orthop Relat Res 2000;(376):26-3I.

II. Shilt JS, Yoder JS, Manuck TA, Jacks L, Rushing J, Smith BP. Role of vacuum-assisted closure in the treatment of pediatric lawnmower injuries. J Pediatr Orthop 2004;24:482-7.

12. Doak J, Ferrick M. Nonoperative management of pediatric grade I 
open fractures with less than a 24 hour admission. J Pediatr Orthop 2009;29:49-5I.

13. Dedmond BT, Kortesis B, Punger K, Simpson J, Argenta J, Kulp $B$, Morykwas M, Webb LX. The use of negative-pressure wound therapy (NPWT) in the temporary treatment of soft-tissue injuries associated with high-energy open tibial shaft fractures.J Orthop Trauma 2007;2I:II-7.

14. Argenta LC, Morykwas MJ. Vacuum-assisted closure: a new method for wound control and treatment: clinical experience. Ann Plast Surg 1997;38:563-76.

15. Morykwas MJ, Simpson J, Punger K, Argenta A, Kremers L, Argenta J. Vacuum-assisted closure: state of basic research and physiologic foundation. Plast Reconstr Surg 2006; I 17:SI21-6.

16. Feldmeier JJ. Problem wounds: the irradiated wound. In: Sheffield PJ, Fife CE, Smith AP, editors. Wound care practice. Flagstaff (AZ): Best Publishing Company; 2004. p. 369-88.

17. Marx RE. Radiation injury to tissue. In: Kindwall EP,Whelan HT editors. Hyperbaric medicine practice. 2nd ed. Flagstaff (AZ): Best Publishing Company; 1999. p. 665-723.

18. Rosenberg LA, Esther RJ, Erfanian K, Green R, Kim HJ, Sweeting R, Tepper JE. Wound complications in preoperatively irradiated softtissue sarcomas of the extremities. Int J Radiat Oncol Biol Phys 2013;85:432-7.

19. Davidge KM, Wunder J, Tomlinson G, Wong R, Lipa J, Davis AM. Function and health status outcomes following soft tissue reconstruction for limb preservation in extremity soft tissue sarcoma. Ann Surg Oncol 2010;17:1052-62.

20. Reddix RN Jr, Leng XI, Woodall J, Jackson B, Dedmond B, Webb
LX. The effect of incisional negative pressure therapy on wound complications after acetabular fracture surgery. J Surg Orthop Adv 2010;19:91-7.

21. Masden D, Goldstein J, Endara M, Xu K, Steinberg J, Attinger C. Negative pressure wound therapy for at-risk surgical closures in patients with multiple comorbidities: a prospective randomized controlled study. Ann Surg 2012;256:1043-7.

22. Webster J, Scuffham P, Stankiewicz M, Chaboyer WP. Negative pressure wound therapy for skin grafts and surgical wounds healing by primary intention. Cochrane Database Syst Rev 2014;10:CD00926I.

23. Stiefel D, Schiestl C, Meuli M. The positive effect of negative pressure: vacuum-assisted fixation of Integra artificial skin for reconstructive surgery.J Pediatr Surg 2009;44:575-80.

24. Citak M, Backhaus M, Meindl R, Muhr G, Fehmer T. Rare complication after VAC-therapy in the treatment of deep sore ulcers in a paraplegic patient. Arch Orthop Trauma Surg 20 I0; I30: I I I I-4.

25. Rentea RM, Somers KK, Cassidy L, Enters J, Arca MJ. Negative pressure wound therapy in infants and children: a single-institution experience.J Surg Res 2013;184:658-64.

26. Lopez G, Clifton-Koeppel R, Emil S. Vacuum-assisted closure for complicated neonatal abdominal wounds. J Pediatr Surg 2008;43:22027.

27. Malmsjö M, Gustafsson L, Lindstedt S, Gesslein B, Ingemansson $R$. The effects of variable, intermittent, and continuous negative pressure wound therapy, using foam or gauze, on wound contraction, granulation tissue formation, and ingrowth into the wound filler. Eplasty 2012;12:e5. 